\title{
Effect of Space on Auditory Temporal Processing with a Single-Stimulus Method
}

\author{
Martin Roy, Tsuyoshi Kuroda and Simon Grondin \\ Université Laval, Québec \\ Canada
}

\section{Introduction}

The exact nature of the relation between space and time is certainly one of the most fundamental issues in physics (Buccheri, Saniga, \& Stuckey, 2003), but it is also an intriguing question for experimental psychologists (Casasanto, Fotakopoulou, \& Boroditsky, 2010). A function of perception is to form mental representations indicating what object exists, where it is located, and how it acts, i.e., how the object moves in space with the lapse of time. Space and time are integrated in the perceptual system to cause the perception of motion and speed, and such integration is required to determine the performance of the motor system (e.g., hand movement; see Lee, 2000). How space and time exert mutual influence is a question that was addressed many years ago (Abe, 1935; Helson, 1930), notably by J. Piaget, who studied the ontogenesis of the relations between time, distance and speed (Piaget, 1955).

Time perception has been often explained with the "internal-clock hypothesis," which is notable in discussing the perceptual relation between space and time. An internal clock is usually assumed to be a pacemaker-counter device, with the first module emitting pulses accumulated by the second one (Grondin, 2001, 2010). The amount of accumulation decides the perceived time duration. The performance level is varied, however, when some variation of nontemporal factors are introduced in experiments. This variability, in a duration discrimination task for instance, can be observed by varying the time intervals' structure (filled or empty; Grondin, 1993), or by varying the sensory modality to be stimulated. Space is a nontemporal factor, which is susceptible to vary the performance level of the internal clock.

There are two illusions concerning the perceptual relation between space and time, which have been studied since the early $20^{\text {th }}$ century (see Jones \& Huang, 1982; Sarrazin, Giraudo, \& Pittenger, 2007; ten Hoopen, Miyauchi, \& Nakajima, 2008). The tau effect takes place typically in the successive presentation of three signals, say, X, Y, and Z, with Y somewhere between X and Z (Helson, 1930; Helson \& King, 1931; Henry, McAuley, \& Zaleha, 2009). They are delivered from different sources spaced at equal intervals, resulting in two equal intervals in space, $\mathrm{X}-\mathrm{Y}$ and $\mathrm{Y}-\mathrm{Z}$. These intervals are perceived as unequal in their distance, however, if the signals are presented at unequal intervals in time; if the time interval defined by $X$ and $Y$ is shorter (longer) than the time interval defined by $Y$ and $Z$, the spatial distance between $X$ and $Y$ is perceived as shorter (longer) than the spatial distance between $Y$ and $Z$. In other words, the spatial-interval ratio is perceived as if it were similar to the time-interval ratio. Such interaction between space and time can be caused in the opposite direction with 
the same signal configuration, i.e., the time-interval ratio is perceived as if it were similar to the spatial-interval ratio. This opposite-direction effect was named the kappa effect (Cohen, Hansel, \& Sylvester, 1953; Price-Williams, 1954).

The kappa effect in the auditory mode was investigated in the present study. The kappa effect has been tested more often in the visual mode (Cohen, Hansel, \& Sylvester, 1953, 1955; Collyer, 1977; Miyatani, 1984-1985; Sarrazin, Giraudo, Pailhous, \& Bootsma, 2004), and even in the tactile mode (Goldreich, 2007; Suto, 1952, 1955, 1957). There are researches testing the kappa effect in the auditory mode, but most of them focused on the effects of frequency distance (difference), instead of spatial distance, on the perception of time duration (Cohen, Hansel, \& Sylvester, 1954; Henry \& McAuley, 2009; Jones \& Huang, 1982; Shigeno, 1986; Yoblick \& Salvendy, 1970). In a typical case, three successive signals were different in their frequency, causing two intervals in time and in frequency, and the time-interval ratio was perceived as if it had been similar to the frequency-interval ratio. There is little evidence for the occurrence of the kappa effect in the perception of space and time in the auditory mode (Sarrazin, Giraudo, Pittenger, 2007; see Ouellet, 2003).

The kappa effect indicates that time duration increases perceptually in proportion to spatial distance between two signals, but this effect has been demonstrated with three successive signals, where two intervals are bounded on each other. Few researches have examined whether or not the similar effect can take place when a single interval is presented.

It is important in this context to indicate that there are cases where time duration is perceived as shorter when spatial distance is increased in the visual mode (Guay \& Grondin, 2001). This result was observed in an experiment employing a single-stimulus method, where a categorization judgment was conducted after the presentation of one interval. The interval was defined by two signals delivered from different sources, which were selected from three sources (above, middle and below) located in front of participants on the same vertical plane. All location pairs were presented in random order within each block. The interval was more often perceived as shorter when it was marked by the above and below sources, in comparison with intervals marked by the above and middle sources or the middle and below sources.

The purpose of the present study was to verify if space exerts influence on time perception (1) when intervals to be measured perceptually are marked by sounds delivered from sources having different distances between them, and (2) when these intervals are presented according to a single-stimulus method.

\section{Method}

\section{Participants}

Twelve 19- to 26-year-old volunteer students at Université Laval (six females and six males) with no hearing problems participated in this experiment. They were paid CAN \$20 for their participation.

\section{Apparatus and stimuli}

A time interval was defined by two sound stimuli of $20 \mathrm{~ms}$. The stimuli were $1-\mathrm{kHz}$ sinusoidal sounds generated by IBM PC running E-Prime software (version 1.1.4.1 - SP3). The computer was equipped with an SB Audigy 2 sound card, and the stimuli were delivered by Logitech Z-640 loudspeakers. Participants pressed " 1 " or " 3 " on the computer keyboard to indicate that the interval was short or long, respectively. 


\section{Procedure}

The single-stimulus method was employed (Allan, 1979; Morgan, Watamaniuk, \& McKee, 2000), i.e., each trial consisted of presenting one interval. The duration of the time intervals was controlled as follows: Eight values of time-interval duration were distributed around a midpoint value which is called the base duration. Four values below the base duration were called the "short" duration, and four values above the base duration were called the "long" duration. There were two base-duration conditions, 125 and $250 \mathrm{~ms}$. In the former case, the "short" intervals lasted 104, 110, 116 and $122 \mathrm{~ms}$, and the "long" intervals 128, 134, 140 and $146 \mathrm{~ms}$. In the latter case, the "short" intervals lasted 208, 220, 232 and $244 \mathrm{~ms}$, and the "long" intervals 256, 268, 280 and $292 \mathrm{~ms}$.

The participants were asked to judge whether the presented interval belonged to the "short" or to the "long" category. A 1.5-s feedback signal was presented immediately after the response on the computer screen and indicated whether the response was correct or not.

There were two conditions of spatial distance between the auditory sources (loudspeakers), $1.1 \mathrm{~m}$ and $3.3 \mathrm{~m}$ (see Figure 1), and there were two conditions of the direction of stimulus presentation, right to left and left to right.

Each participant completed eight sessions, four for 125-ms base duration and four for 250ms base duration. Six participants completed the 125 -ms sessions before the $250-\mathrm{ms}$ sessions, and six completed the 250-ms sessions before the 125-ms sessions. Four sessions in each base duration corresponded to four spatial conditions (2 distances $\times 2$ directions), and they were carried out in random order. Each session had six blocks of 64 trials where the eight intervals were presented eight times in random order, and thus 48 responses were obtained in each interval in each spatial condition.

\section{Data analysis}

The two direction conditions were collapsed, resulting in four conditions in the data analysis ( 2 distance and 2 base-duration conditions). For each participant and for each condition, an 8-point psychometric function was traced, plotting the time interval duration on the $x$-axis and the "long" response proportion on the y-axis. Each point on the psychometric function was based on 96 presentations.

The pseudo-logistic model (Killeen, Fetterman, \& Bizo, 1997) was employed to calculate psychometric functions that were fitted to the resulting curves. Two indices of performance were estimated from each psychometric function, one for sensitivity and one for perceived duration. As an indicator of temporal sensitivity, one standard deviation (SD) on each psychometric function was employed. Using one SD (or variance) is a common procedure to express temporal sensitivity (Grondin, 2008; Grondin, Roussel, Gamache, Roy, \& Ouellet, 2005; Killeen \& Weiss, 1987).

The other parameter was the temporal bisection point (BP). In the context of the kappa effect, this dependent variable is the most important. The BP can be defined as the $x$ value corresponding to the 0.50 proportion on the $y$-axis. The observed shift of the BP for different conditions can be interpreted as an indication of differences in perceived duration. If an interval is perceived as longer, the "long" response takes place more frequently, which causes the downward shift of the BP. If an interval is perceived as shorter, the "long" response takes place less frequently, which causes the upward shift of the BP.

\section{Results}

Figure 2 reports the grouped psychometric function for each of the four experimental conditions: 2 Distances $\times 2$ Base Durations. In order to allow direct comparisons between the 
base duration conditions, two dependent variables were calculated from the above parameters. One is the Constant Error, which is the BP minus the base duration. The other is the Coefficient of Variation, which is the SD divided by the BP.

Figure 3 shows the results for the Constant Error. Essentially, it reveals higher values in the 3.3-m condition than in the 1.1-m condition. A $2 \times 2$ ANOVA with repeated measures revealed that both the distance effect, $F(1,11)=10.55, p<.01, \eta_{p}^{2}=.49$ and the base duration effect, $F(1,11)=4.91, p<.05, \eta_{p}{ }^{2}=.31$, were significant. The interaction effect was also significant, $F(1,11)=8.36, p<.05, \eta_{p}^{2}=.43$.

Figure 4 shows the results for the Coefficient of Variation. The $2 \times 2$ ANOVA with repeated measures revealed that both the distance effect, $F(1,11)=7.23, p<.05, \eta_{p}{ }^{2}=.40$, and the base duration effect, $F(1,11)=19.80, p<.001, \eta_{p}^{2}=.64$, were significant. The interaction effect was not significant, $F(1,11)=.60, p=.45, \eta_{p}{ }^{2}=.05$.

\section{Discussion}

The results of the present experiment clearly indicate that increasing the distance between sound sources marking time intervals leads to a decrease of the perceived duration (a higher constant error). These results are inconsistent with what is usually reported when referring to the kappa effect but consistent with results obtained in the visual mode with a singlestimulus method (Guay \& Grondin, 2001). Other results linking space and time in the auditory mode revealed no such effect of distance between sound sources when sequences of four sounds from four sources were used (Ouellet, 2003). The present experiment also revealed that increasing distance between marker's sources results in a higher coefficient of variation.

The present results can be explained on the basis of the internal-clock hypothesis, where the accumulation process is controlled by an attentional mechanism, with more attention to time resulting in a higher accumulation of pulses (Grondin \& Macar, 1992; Grondin \& Plourde, 2007; Macar, Grondin, \& Casini, 1994). When the two stimuli were farther away from each other in space, more attentional resources were allocated to their location perception (Mondor \& Zattore, 1995; Rhodes, 1987; Roussel, Grondin, \& Killeen, 2009), which caused the decrease of the resources allocated to the time perception. There were less accumulated pulses in the counter of the internal clock, and thus the time duration was perceived as shorter. This explanation is also consistent with the results obtained with the coefficient of variation. Allocating more resources to the spatial perception caused more variance (more categorization errors - higher coefficient of variation) in the observers' judgment.

Finally, the results also revealed higher coefficients of variation in the 125-ms base duration than in the 250-ms base duration. This finding is consistent with a generalized form of Weber's law applied to time perception in which sensory noise (nontemporal noise due to attention disturbance) causes more damage to performance with briefer intervals.

\section{Acknowledgements}

This research was made possible by a grant awarded to SG by the Natural Sciences and Engineering Research Council of Canada (NSERC). We would like to thank Marie-Claude Simard and Karine Drouin for their help with data collection. Correspondence should be addressed to Simon Grondin, École de psychologie, 2325 rue des Bibliothèques, Université Laval, Québec, Qc, Canada, G1V 0A6 (E-mail: simon.grondin@psy.ulaval.ca) 


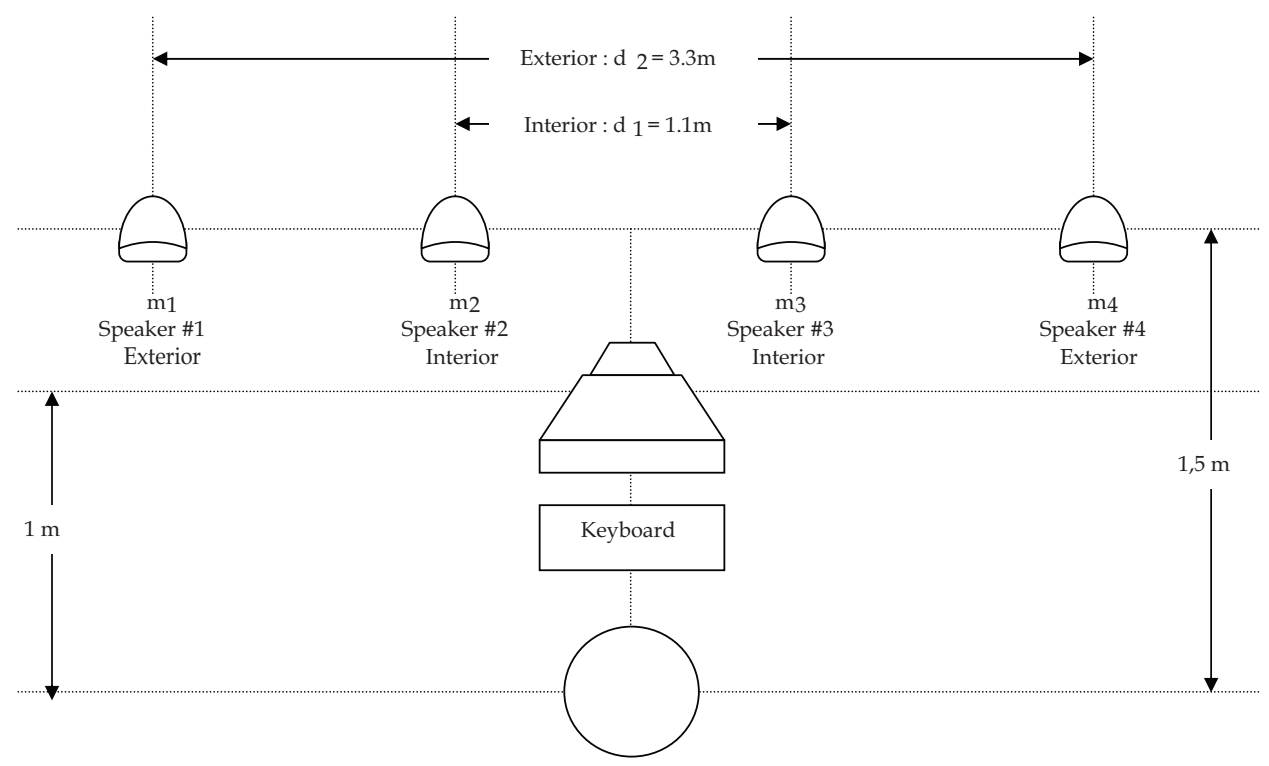

Fig. 1. Experimental set-up 

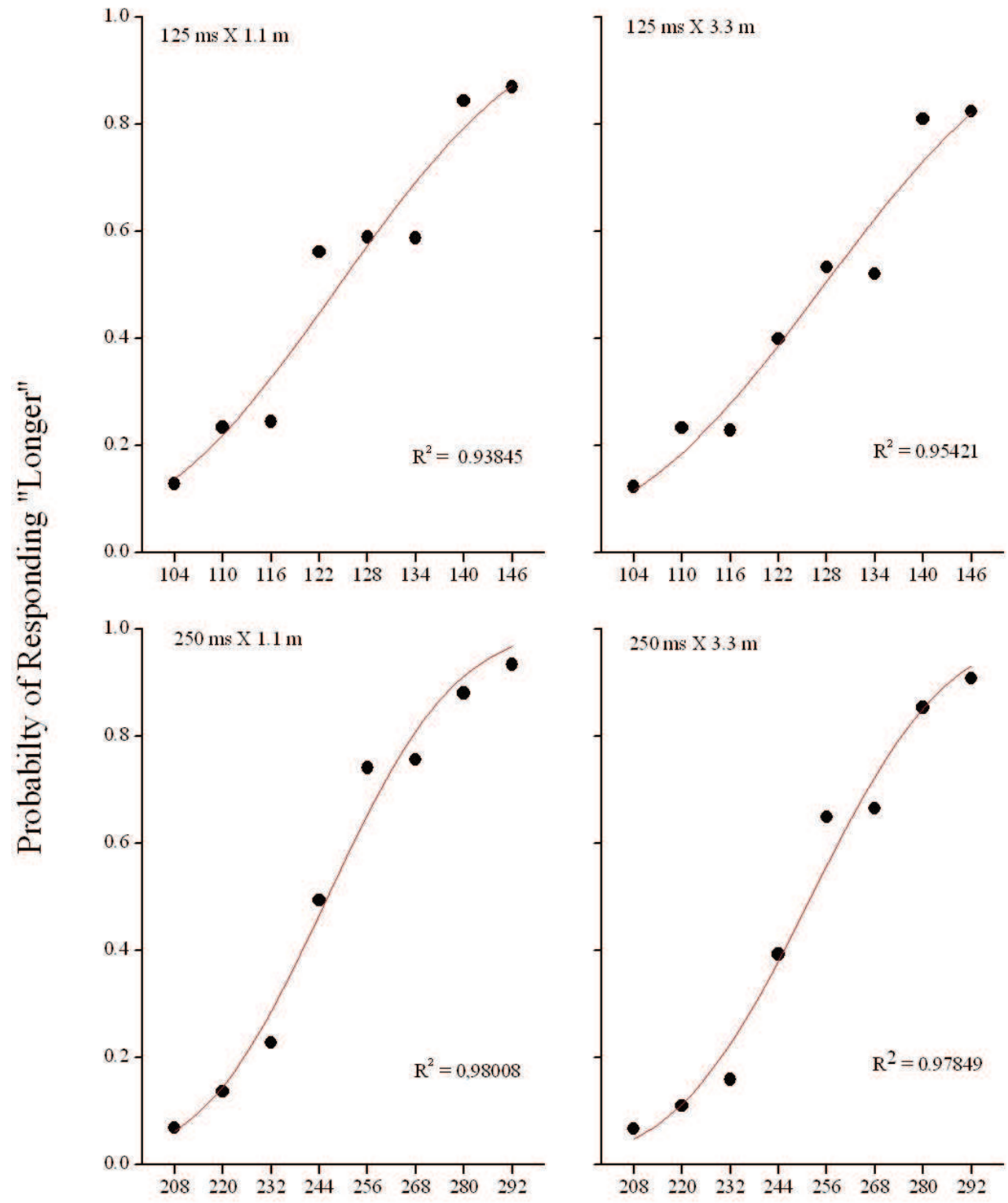

Comparison Interval (ms)

Fig. 2. Psychometric function (grouped data) in each experimental condition. 


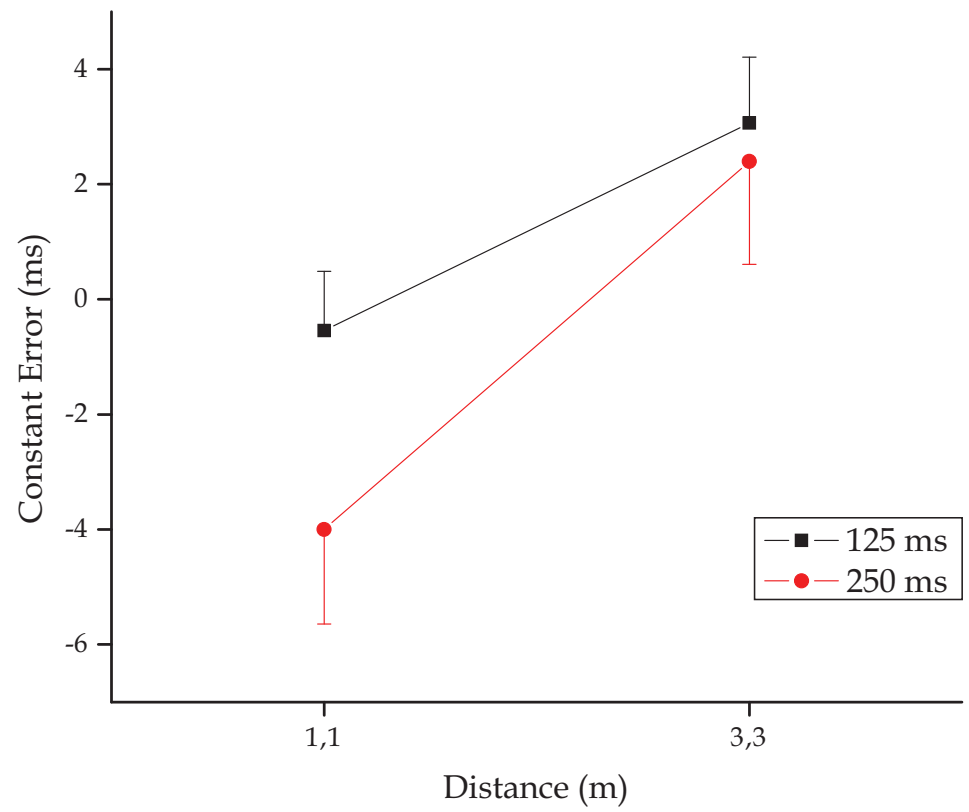

Fig. 3. Mean Constant Error as a function of distance between auditory markers. (Bars are standard errors)

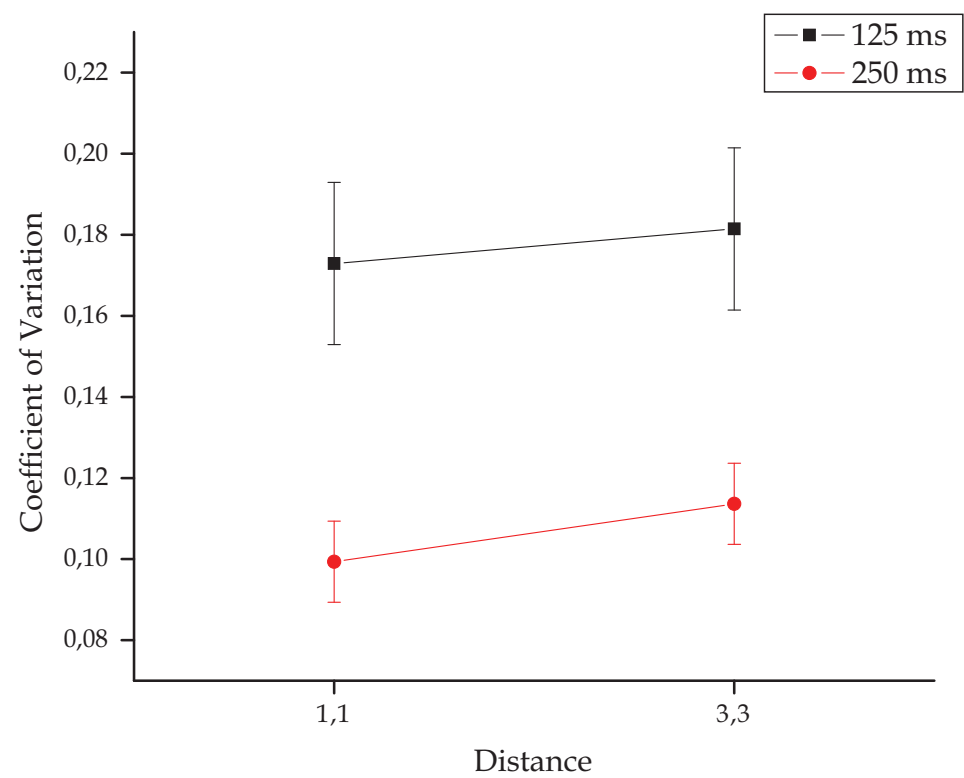

Fig. 4. Mean Coefficient of Variation as a function of distance between auditory markers. (Bars are standard errors) 


\section{References}

Abe, S. (1935). Experimental study on the co-relation between time and space. Tohoku Psychologica Folia, 3, 53-68.

Allan, L. G. (1979). The perception of time. Perception \& Psychophysics, 26, 340-354.

Buccheri, R., Saniga, M., \& Stuckey, W. M. (Eds.). (2003). The Nature of Time: Geometry, Physics and Perception. Dordrecht, Netherlands: Kluwer Academic Publishers.

Casasanto, D., Fotakopoulou, O., \& Boroditsky, L. (2010). Space and time in the child's mind: Evidence for a cross-dimensional asymmetry. Cognitive Science, 34, 387-405.

Cohen, J., Hansel, C. E. M., \& Sylvester, J. D. (1953). A new phenomenon in time judgment. Nature, 172, 901.

Cohen, J., Hansel, C. E. M., \& Sylvester, J. D. (1954). Interdependence of temporal and auditory judgments. Nature, 174, 642-644.

Cohen, J., Hansel, C. E. M., \& Sylvester, J. D. (1955). Interdependence in judgments of space, time and movement. Acta Psychologica, 11, 360-372.

Collyer, C. E. (1977). Discrimination of spatial and temporal intervals defined by three light flashes: Effects of spacing on temporal judgments and of timing on spatial judgments. Perception E Psychophysics, 21, 357-364.

Goldreich, D. (2007). A Bayesian perceptual model replicates the cutaneous rabbit and other tactile spatiotemporal illusions. PLoS ONE, 2, e333.

Grondin, S. (1993). Duration discrimination of empty and filled intervals marked by auditory and visual signals. Perception \& Psychophysics, 54, 383-394.

Grondin, S. (2001). From physical time to the first and second moments of psychological time. Psychological Bulletin, 127, 22-44.

Grondin, S. (2008). Methods for studying psychological time. In S. Grondin (Ed.). Psychology of time (pp. 51-74). Bingley, UK: Emerald Group Publishing.

Grondin, S. (2010). Timing and time perception: A review of recent behavioral and neuroscience findings and theoretical directions. Attention, Perception, $\mathcal{E}$ Psychophysics, 72, 561-582.

Grondin, S., \& Macar, F. (1992). Dividing attention between temporal and nontemporal tasks: A performance operating characteristic -POC- analysis. In F. Macar, V. Pouthas, \& W. J. Friedman (Eds.), Time, Action, Cognition: Towards Bridging the Gap. (pp. 119-128). Dordrecht, Netherlands: Kluwer Academic Publishers.

Grondin, S., \& Plourde, M. (2007). Discrimination of time intervals presented in sequences: Spatial effects with multiple auditory sources. Human Movement Science, 26, 702716.

Grondin, S., Roussel, M.-È., Gamache, P.-L., Roy, M., \& Ouellet, B. (2005). The structure of sensory events and the accuracy of time judgments. Perception, 34, 45-58.

Guay, I., \& Grondin, S. (2001). Influence on time interval categorization of distance between markers located on a vertical plane. In E. Sommerfeld, R. Kompass, \& T. Lachman (Eds.), Proceedings of the 17th Annual Meeting of the International Society for Psychophysics (pp. 391-396). Berlin, Germany: Pabst Science Publishers.

Helson, H. (1930). The tau effect: An example of psychological relativity. Science, 71, 536537.

Helson, H., \& King, S. M. (1931). The tau effect: An example of psychological relativity. Journal of Experimental Psychology, 14, 202-217. 
Henry, M. J. \& McAuley, J. D. (2009). Evaluation of an imputed pitch velocity model of the auditory kappa effect. Journal of Experimental Psychology: Human Perception and Performance, 35, 551-564.

Henry, M. J., McAuley, J. D., \& Zaleha, M. (2009). Evaluation of an imputed pitch velocity model of the auditory tau effect. Attention, Perception \& Psychophysics, 71, 1399-1413.

Jones, B., \& Huang, Y. L. (1982). Space-time dependencies in psychophysical judgment of extent and duration: Algebraic models of the tau and kappa effect. Psychological Bulletin, 91, 128-142.

Killeen, P. R., Fetterman, J. G., \& Bizo, L. A. (1997). Time's cause. In C. M. Bradshaw \& E. Szabadi (Eds). Time and Behavior: Psychological and Neurobehavioral Analyses (pp. 79131). Amsterdam, Netherlands: North-Holland/Elsevier Science.

Killeen, P. R., \& Weiss, N. A. (1987). Optimal timing and the Weber function. Psychological Review, 94, 455-468.

Lee, D. (2000). Learning of spatial and temporal patterns in sequential hand movements. Cognitive Brain Research, 9, 35-39.

Macar, F., Grondin, S., \& Casini, L. (1994). Controlled attention sharing influences time estimation. Memory \& Cognition, 22, 673-686.

Mondor, T. A., \& Zattore, R. J. (1995). Shifting and focusing auditory spatial attention. Journal of Experimental Psychology: Human Perception and Performance, 21, 387-409.

Morgan, M. J., Watamaniuk, S. N. J., \& McKee, S. P. (2000). The use of an implicit standard for measuring discrimination thresholds. Vision Research, 40, 2341-2349.

Miyatani (1984-1985). The time and distance judgments at different levels of discriminability of temporal and spatial information. Hiroshima Forum for Psychology, 10, 45-55.

Ouellet, B. (2003). L'influence de la distance entre des marqueurs statiques sur la discrimination d'intervalles temporels: À la recherche de l'effet kappa classique en modalité auditive. Unpublished master's dissertation, Université Laval, Québec, Canada.

Piaget, J. (1955). The development of time concepts in the child. In P. H. Hoch, J. Zubin (Eds.), Psychopathology of Childhood (pp. 34-44). New York, USA: Grune \& Stratton.

Price-Williams, D. R. (1954). The kappa effect. Nature, 173, 363-364.

Rhodes, G . (1987). Auditory attention and the representation of spatial information. Perception \& Psychophysics, 42, 1-14.

Roussel, M.-E., Grondin, S., \& Killeen, P. (2009). Spatial effects on temporal categorization. Perception, 38, 748-762.

Sarrazin, J.-C., Giraudo, M.-D., Pailhous, J., \& Bootsma, R. J. (2004). Dynamics of balancing space and time in memory: Tau and kappa effects revisited. Journal of Experimental Psychology: Human Perception and Performance, 30, 411-430.

Sarrazin, J.-C., Giraudo, M.-D., \& Pittenger, J. B. (2007). Tau and kappa effects in physical space: The case of audition. Psychological Research, 71, 201-218.

Shigeno, S. (1986). The auditory tau and kappa effects for speech and nonspeech stimuli. Perception \& Psychophysics, 40, 9-19.

Suto, Y. (1952). The effect of space on time estimation (S-effect) in tactual space. I. Japanese Journal of Psychology, 22, 45-57.

Suto, Y. (1955). The effect of space on time estimation (S-effect) in tactual space. II : The role of vision in the S effect upon skin. Japanese Journal of Psychology, 26, 94-99.

Suto, Y. (1957). Role of apparent distance in time perception. Research Reports of Tokyo Electrical Engineering College, 5, 73-82. 
ten Hoopen, G., Miyauchi, R., \& Nakajima, Y. (2008). Time-based illusions in the auditory mode. In S. Grondin (Ed.). Psychology of Time (pp. 139-188). Bingley, UK: Emerald Group Publishing.

Yoblick, D. A., \& Salvendy, G. (1970). Influence of frequency on the estimation of time for auditory, visual, and tactile modalities: The kappa effect. Journal of Experimental Psychology, 86, 157-164. 


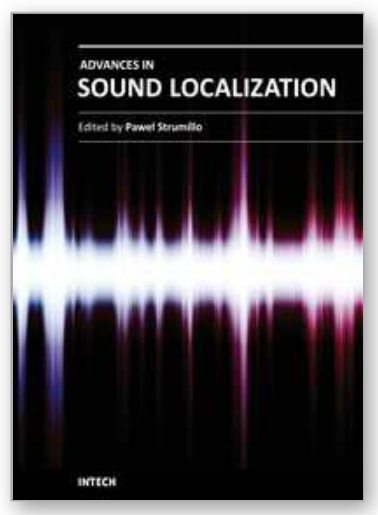

\author{
Advances in Sound Localization \\ Edited by Dr. Pawel Strumillo
}

ISBN 978-953-307-224-1

Hard cover, 590 pages

Publisher InTech

Published online 11, April, 2011

Published in print edition April, 2011

Sound source localization is an important research field that has attracted researchers' efforts from many technical and biomedical sciences. Sound source localization (SSL) is defined as the determination of the direction from a receiver, but also includes the distance from it. Because of the wave nature of sound propagation, phenomena such as refraction, diffraction, diffusion, reflection, reverberation and interference occur. The wide spectrum of sound frequencies that range from infrasounds through acoustic sounds to ultrasounds, also introduces difficulties, as different spectrum components have different penetration properties through the medium. Consequently, SSL is a complex computation problem and development of robust sound localization techniques calls for different approaches, including multisensor schemes, nullsteering beamforming and time-difference arrival techniques. The book offers a rich source of valuable material on advances on SSL techniques and their applications that should appeal to researches representing diverse engineering and scientific disciplines.

\title{
How to reference
}

In order to correctly reference this scholarly work, feel free to copy and paste the following:

Martin Roy, Tsuyoshi Kuroda and Simon Grondin (2011). Effect of Space on Auditory Temporal Processing with a Single-Stimulus Method, Advances in Sound Localization, Dr. Pawel Strumillo (Ed.), ISBN: 978-953-307224-1, InTech, Available from: http://www.intechopen.com/books/advances-in-sound-localization/effect-ofspace-on-auditory-temporal-processing-with-a-single-stimulus-method

\section{INTECH}

open science | open minds

\section{InTech Europe}

University Campus STeP Ri

Slavka Krautzeka 83/A

51000 Rijeka, Croatia

Phone: +385 (51) 770447

Fax: +385 (51) 686166

www.intechopen.com

\section{InTech China}

Unit 405, Office Block, Hotel Equatorial Shanghai

No.65, Yan An Road (West), Shanghai, 200040, China

中国上海市延安西路65号上海国际贵都大饭店办公楼405单元

Phone: +86-21-62489820

Fax: $+86-21-62489821$ 
(C) 2011 The Author(s). Licensee IntechOpen. This chapter is distributed under the terms of the Creative Commons Attribution-NonCommercialShareAlike-3.0 License, which permits use, distribution and reproduction for non-commercial purposes, provided the original is properly cited and derivative works building on this content are distributed under the same license. 